\title{
INTERNAÇÃO CONJUNTA: OPINIÃO DA EQUIPE DE ENFERMAGEM*
}

\author{
STAYING TOGETHER: THE NURSING STAFF OPINION \\ INTERNACIÓN CONJUNTA: LA OPINIÓN DEL EQUIPO DE ENFERMERÍA
}

\section{Kellen Litchteneker ${ }^{1}$ Rosângela Aparecida Pimenta Ferrari ${ }^{2}$}

\begin{abstract}
RESUMO: Trata-se de um estudo de natureza descritiva cujo objetivo foi analisar a opinião da equipe de enfermagem em relação à internação conjunta da unidade pediátrica de um hospital público. A coleta de dados foi através de um formulário com questões abertas e fechadas. A população do estudo foi de 28 profissionais da equipe de enfermagem do sexo feminino, com predominância na faixa etária dos 31 aos 40 anos de idade. $\mathrm{Na}$ sua maioria, trabalhavam na unidade de 1 a 5 anos. Com relação à opinião dos funcionários sobre a internação conjunta $53 \%$ referiram significar uma recuperação rápida e $44 \%$ como direito da criança. As facilidades e as dificuldades da internação conjunta referida pelos profissionais sobre as crianças, foram que estas não se adaptam com o ambiente hospitalar e que os acompanhantes influenciam negativamente na execução dos procedimentos. Porém fornecem mais segurança para as crianças. A infra-estrutura e planta física não oferecem condições necessárias para a internação conjunta. Através dos resultados deste estudo demonstra-se à necessidade de educação continuada para os profissionais para a melhoria das relações humanas e interpessoais e também a elaboração de um protocolo para melhor orientação da rotina e normas da unidade pediátrica pela equipe de enfermagem.
\end{abstract}

\section{PALAVRAS-CHAVE: Criança; Hospitalização; Direitos da criança.}

ABSTRACT: This is descriptive study, which aims to analyze the nursing staff opinion about the family staying together in the hospital with the child in a Public Hospital. The data was collect through a form with open - closed questions. Study population was 28 professional nursing staff, only female and aged from 31 to 40 years old. Most of them have been working in the Unit from one to 5 years. About the opinion of staying in the Hospital, $53 \%$ of the professionals referred as something positive since it provides fast recovering and $44 \%$ of them mentioned the children's right. The facilities and difficulties of staying together in the hospital referred by professionals was that, children do not adapt themselves to the hospital atmosphere and the family companion influence negatively while assistance procedures are execute, although they are able to offer more security to the children. The infrastructure does not offer the necessary conditions for familiar staying together the child in the hospital. From these results, it is possible to perceive that is necessary the continuous education for professionals to enhance the human and interpersonal relationship and a nursing protocol elaboration to improve the routine and rules orientation in the Pediatric Unit.

KEYWORDS: Child; Hospitalization; Children rights.

RESUMEN: Estudio descriptivo con objetivo de analizar la opinión de los enfermeros sobre la familia que permanece junto con el niño en un hospital público. Los datos fueron colectados por medio de un formulario con preguntas cerradas y abiertas. La población del estudio fueran 28 enfermeras, del sexo femenino, entre los 31 y 40 años de edad. La mayoría de ellos han trabajado en la unidad de un a cinco años. Sobre la opinión de permanecer en el hospital, $53 \%$ de los profesionales se refirieron como algo positivo puesto que proporciona rápidamente la recuperación y el $44 \%$ de ellos mencionaron a los derechos de los niños. Las facilidades y las dificultades de permanecer juntas en el hospital referido por los profesionales, eran que los niños no se adapta a la atmósfera del hospital, y la influencia negativa del acompañante cuando se ejecutan los procedimientos de enfermería, aunque pueden ofrecer más seguridad a los niños. La infraestructura no ofrece las condiciones necesarias para el familiar que permanece junto al niño en el hospital. De estos resultados, es posible percibir que es necesario la educación continua para los profesionales para realizar las relaciones humanas e interpersonales y la elaboración del protocolo de enfermería para mejorar la rutina y orientaciones en la unidad pediátrica.

PALABRAS CLAVES: Niño; Hospitalización; Derechos del niño.

\section{INTRODUÇÃO}

Os primeiros anos de vida da criança são considerados os mais vulneráveis. Neste período ela não vive por si mesma sendo totalmente dependente da família. A criança necessita de orientação, referência de tempo e proteção para o desconhecido e para o sofrimento.

Segundo FERREIRA et al (1996) a criança não pode ser compreendia de forma isolada, desconsiderando o todo como ser humano e o seu contexto histórico, na qual está inserida, além também, das necessidades de cuidados para o corpo, com 
alimentação e aprendizado. A ligação afetiva entre a criança e a família, e mais objetivamente com a mãe é imprescindível para assegurar que as bases de formação psicológica do futuro adulto sejam mantidas intactas. O elo entre a criança e a mãe ocorre desde o período de gravidez, nascimento, amamentação, cuidado e proteção de mãe para filho (IMORI et al, 1997).

Entretanto, durante o período infantil, a criança pode encontrar situação de privação do convívio familiar por diferentes motivos, sendo um delas a hospitalização (OLIVEIRA \& COLLET, 1999). As reações da criança à doença frente à hospitalização dependem principalmente do nível de desenvolvimento psíquico na ocasião da internação, grau de apoio familiar, tipos de doença e do grau de apoio médico (BALDINI \& KREBS, 1999).

A hospitalização para a criança traz um sentimento de ameaça, agressão, medo do desconhecido, pois é nesse momento que ocorre a separação de todos os objetos significativos de sua segurança, por outro lado a família retorna para casa cheia de angústia, ansiedade e sentimento de culpa (CASTRO, 1991).

Segundo OLIVEIRA \& ÂNGELO (2000) a hospitalização altera tanto a vida da criança como a dinâmica familiar. Referem ainda que a doença seja um processo que provoca mudanças no cotidiano da família, necessitando de novas organizações de suas atividades. Além dos sentimentos de angústias, impotência, preocupação e incerteza, também há sofrimento por ambas as partes, devido à estreita ligação família-criança que se rompe durante a este período.

Embora os fatores que influenciam na resposta da criança à problemática da hospitalização, bem como as vivências sejam muito variados, a ausência total ou parcial do familiar possui o maior peso no processo de adaptação e desabituação da criança no ambiente hospitalar (SCHMITZ, 2000). A hospitalização é quase sempre um duplo traumatismo, pois ela tem que se separar do ambiente familiar e entrar num ambiente hostil que é o hospital. A presença da família na assistência da criança hospitalizada é de grande importância, contribuindo para torná-la capaz de suportar os sofrimentos e ansiedades surgidas durante a doença e a hospitalização.

Segundo HUERTA (1984), a presença do acompanhante junto à criança hospitalizada tem sido vista como benéfica, pois há ajuda na recuperação da criança, provocando sentimento de competência e realização, além de diminuir a permanência nos hospitais e as infecções hospitalares. Apesar dos benefícios encontrados, há divergências nas relações equipe e acompanhante, surgindo sofrimento e luta para enfrentar a negociação dos costumes em relação ao funcionamento da unidade (COLLET \& ROCHA, 2003). Os profissionais de saúde parecem em algumas situações, não perceber que na ausência da mãe a criança requer mais atenção, carinho e proximidade (OLIVEIRA \& COLLET, 1999).
Estes acontecimentos, muitas vezes fazem com que a ligação equipe e acompanhante torne-se dificultosa, não cumprindo a rotina pré-estabelecida para o andamento da unidade, surgindo confrontos e desavenças. Portanto, a realização deste estudo tem como finalidade analisar a opinião da equipe de enfermagem sobre o processo da Internação Conjunta na unidade pediátrica de um hospital escola, por ser este um problema no cotidiano da relação equipe e acompanhante.

\section{METODOLOGIA}

Trata-se de uma pesquisa quantitativa descritiva. Os dados foram coletados na unidade de internação pediátrica do Hospital Universitário - HU do município de Londrina, região norte do Paraná.

O município de Londrina possui cerca de 478.000 habitantes e três hospitais de grande porte, dos quais um é o HU que se caracteriza como um hospital terciário que atende pacientes exclusivamente do Sistema Único de Saúde - SUS, considerado como referência para o Paraná e outros Estados. Atende todas as especialidades, inclusive a pediátrica. A unidade pediátrica possui 34 leitos. Deste total, 10 leitos são para as cirurgias, 05 leitos para as especialidades (oftalmologia, neurologia e neurocirurgia, ortopedia, otorrinolaringologia) e 19 leitos da pediatria geral.

A Internação Conjunta na unidade pediátrica do HU está implantada desde 1992, obedecendo a Lei de 13 de julho de 1990 e o Estatuto da Criança e do Adolescente.

A população de estudo foi constituída pelos profissionais da equipe de enfermagem entre eles: enfermeiro, técnico de enfermagem, auxiliar de enfermagem e escriturário dos três turnos de trabalho (matutino vespertino e noturno). A coleta de dados foi realizada no mês de agosto de 2004 sendo utilizado um formulário com perguntas fechadas e abertas. O formulário foi entregue para cada funcionário responder no local de trabalho e recolhido posteriormente.

Os dados foram analisados e agrupados conforme a afinidade e a freqüência das respostas obtidas no formulário e tabulados no programa Excel.

O estudo foi realizado após a aprovação do Projeto de Pesquisa pelo Comitê de Ética da Universidade Estadual de Londrina, tendo como parecer CEP 156/04, atendendo a resolução nº 196 de 10 de outubro de 1996, do Conselho Nacional de Saúde, que predispõe normas de regulamentação de pesquisa com seres humanos (BRASIL, 1996).

\section{RESULTADOS E DISCUSSÃO}

Os resultados a seguir apresentados dizem respeito aos 28 formulários $(62,2 \%)$ preenchidos pelos profissionais da equipe de enfermagem da unidade pediátrica do HU do município de Londrina no mês de agosto do ano de 2004. A equipe atuante na Unidade Pediátrica no mês da pesquisa era composta por 45 profissionais. A totalidade dos enfermeiros e 
escriturários participou da pesquisa enquanto que sete auxiliares de enfermagem não participaram e outros se encontravam em licença ou férias.

O total dos profissionais era do sexo feminino, sendo que $64,3 \%$ (18) casadas e $75 \%$ (21) e tinha filhos, média de 2,3 filhos/profissional.

Com relação à faixa etária 47\% tinham entre 31 a 40 anos de idade, seguido pela idade entre 41 a 50 anos (42,8\%), 57\% tinham mais de 16 anos tempo de profissão e cerca de $30 \%$ trabalhavam na unidade pediátrica há mais de um ano.

Pode-se observar que prevalecem na unidade pediátrica, mulheres, mães e trabalhadoras prestando assistência às mães, crianças e família no processo de adoecimento.

Apesar do número predominante de mulheres na unidade pediátrica, a criança também necessita da figura masculina para seu desenvolvimento, inclusive durante a hospitalização, concordes com alguns autores, a figura masculina presente na equipe de enfermagem poderia propiciar melhor acolhimento para criança no seu período de desenvolvimento da infância.

Segundo GOMES \& RESENDE (2004) a figura paterna representa a possibilidade do equilíbrio pensando como regulador da capacidade da criança investir no mundo real, ganhando contorno no processo de crescimento, de acordo com a etapa da infância.

Opinião dos profissionais da equipe de enfermagem sobre o significado da Internação Conjunta na unidade pediátrica.

Com a implementação da Internação Conjunta nas unidades pediátricas, conseqüentemente houve a enfatização da importância de ter alguém da família ou conhecido por perto da criança hospitalizada. Há serviços que programaram o programa apenas para cumprir a lei, porém é preciso garantir e proporcionar qualidade ao acompanhante, bem como conscientizar o cidadão sobre os seus direitos, resgatando os aspectos éticos e de humanização da assistência (COSTENARO et al, 1998).

Pode-se observar na Figura 1 que mais de 53\% dos profissionais referiram que a IC significa um meio de rápida recuperação para a criança e para $44 \%$ que é um direito da criança.

Figura 1 Distribuição dos profissionais da equipe de enfermagem da unidade pediátrica de um hospital escola público, segundo a opinião do significado da internação conjunta, Londrina-PR, 2004.

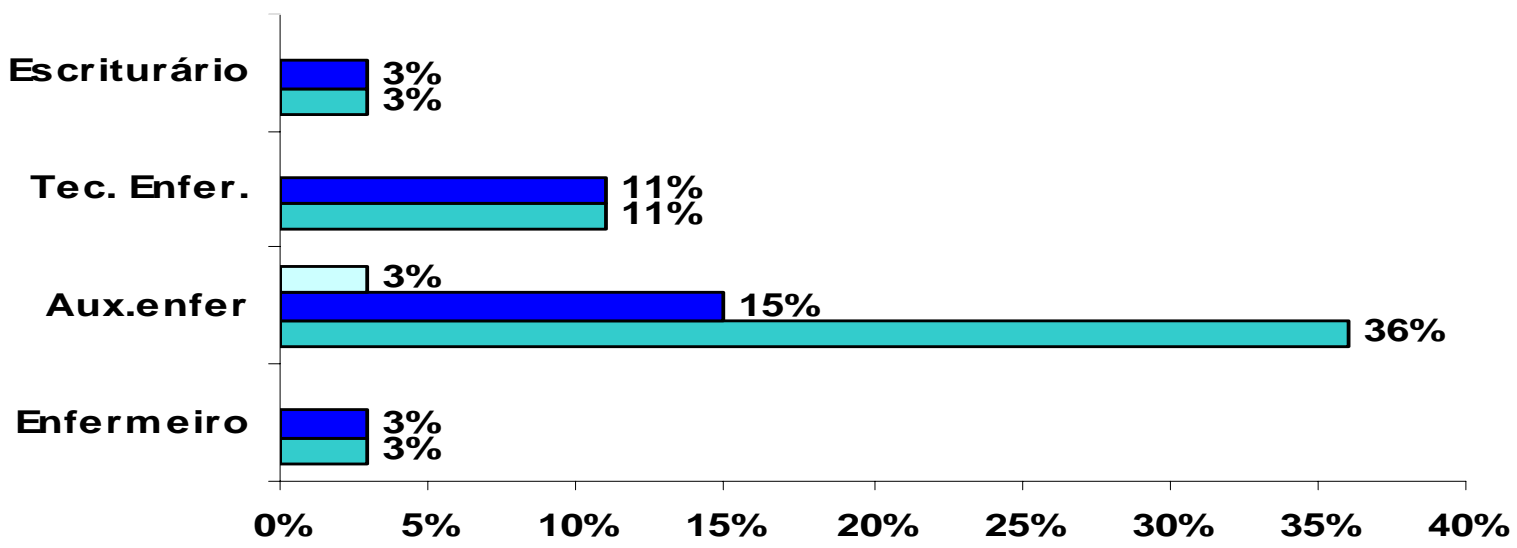

Recupe ração rápida da criança $\square$ Direito da criança $\square$ não respondeu

Segundo COLLET \& ROCHA (2003), a presença do acompanhante faz com que a criança tenha uma recuperação rápida e menos dolorosa com sua atenção e carinho.

Quanto às respostas descritas pelos profissionais deste estudo, também apontam os benefícios da IC à criança, enunciados a seguir:

Mais amor, carinho ajuda na recuperação rápida e com menos sofrimento... (auxiliar de enfermagem).
Fundamental para o bem estar da criança e para sua recuperação (técnico de enfermagem).

A criança muda de ambiente de pessoas tudo novo e a internação conjunta traz um pouco de ambiente familiar para que ela aceite o tratamento com mais facilidade (auxiliar de enfermagem).

Um dos discursos refere-se à importância do acompanhante durante a hospitalização da criança, 
pois é uma figura de confiança e que pode dar atenção e carinho em tempo integral.

Para a criança permanecer com a mãe, para mãe permanecer com sua "cria", mãe e filho não devem ser separados (enfermeira).

Além da recuperação rápida, os profissionais da equipe de enfermagem têm em mente a grande importância da humanização, e atender aos direitos da criança, conforme o artigo 12 do ECA, o qual estabelece a permanência do acompanhante com a criança.

Segundo SILVA \& RIBEIRO (2000) um cuidado humanizado por parte da equipe multiprofissional que trabalha junto à criança, sensível às suas necessidades e angústias, bem como às de sua família, contribui para diminuir o impacto da internação na vida da criança e daqueles que a cercam.

Da mesma forma que SILVA \& RIBEIRO (2000) os profissionais deste estudo, também se referem à IC como um ato de humanização. É o que revela as falas a seguir:

É uma forma de humanização, porque ajuda a criança em sua recuperação, intrahospitalar, tendo a mãe ou outro familiar a seu lado, a criança sentirá menos trama e com certeza o tratamento será mais produtivo (auxiliar de enfermagem).

É muito importante pelos benefícios da presença materna durante a internação, auxiliando e diminuindo o período de internação (escrituraria).

A permanência de um dos pais acompanhantes faz com que haja possibilidade de que as conseqüências da hospitalização da criança sejam minimizadas, inclusive diminuindo o tempo de permanência no hospital.
No Hospital Pequeno Príncipe, localizada na cidade de Curitiba, Estado do Paraná, onde o tempo médio de internação hospitalar da criança era de 12 dias e, após a implementação do programa de Internação Conjunta na unidade pediátrica, o tempo de internação da criança diminuiu para 5 dias, disponibilizando $75 \%$ dos leitos (SOBECC, 2002).

Portanto, a melhoria da qualidade da assistência em saúde da criança não é apenas a excelência técnica e cientifica, mas sim a prática humanizada no cuidar da criança hospitalizada, garantida em lei há mais de 13 anos.

\section{OPINIÃO DOS PROFISSIONAIS DA EQUIPE DE ENFERMAGEM QUANTO ÀS FACILIDADES E DIFICULDADES FRENTE À ROTINA DA IC PARA A CRIANÇA, MÃEIACOMPANHANTE E EQUIPE DE ENFERMAGEM.}

Opinião dos profissionais da equipe de enfermagem sobre as facilidades e as dificuldades da criança durante o período de internação na unidade pediátrica.

$\mathrm{O}$ ato de cuidar em enfermagem pediátrica em relação à criança tem a família como núcleo de atenção, implicando assim, que a criança está inserida numa família com uma história própria, que por sua vez, pertence a um grupo social com todas as determinações histórica e cultural (KAKEHASHI \& SILVA, 2001).

$\mathrm{Na}$ Tabela 1, pode-se observar que $80 \%$ das enfermeiras, $47,6 \%$ dos técnicos e auxiliares de enfermagem e $100 \%$ dos escriturários consideraram que uma das facilidades da IC para a criança era a vantagem de ter alguém por perto, enquanto que $47,6 \%$ dos técnicos e auxiliares de enfermagem e $20 \%$ das enfermeiras referiram ser um fator de recuperação rápida.

Tabela 1 Distribuição dos profissionais da equipe de enfermagem da unidade pediátrica de um hospital-escola público, segundo as opiniões sobre as facilidades encontradas pela criança durante a internação conjunta, Londrina-PR, 2004.

\begin{tabular}{|c|c|c|c|c|c|c|c|c|}
\hline \multirow[t]{2}{*}{ Opinião quanto às facilidades } & \multicolumn{2}{|c|}{ Enfermeira } & \multicolumn{2}{|c|}{ Téc. e Aux. Enf } & \multicolumn{2}{|c|}{ Escrituraria } & \multicolumn{2}{|c|}{ TOTAL } \\
\hline & $n^{\circ}$ & $\%$ & $n^{\circ}$ & $\%$ & $n^{0}$ & $\%$ & $n^{0}$ & $\%$ \\
\hline Direito por ter alguém por perto & 4 & 80,0 & 10 & 47,6 & 2 & 100,0 & 16 & 57,1 \\
\hline Ter uma recuperação rápida & 1 & 20,0 & 10 & 47,6 & - & - & 11 & 39,3 \\
\hline Tem facilidade & 0 & 0 & 1 & 4,8 & - & - & 1 & 3,6 \\
\hline TOTAL & 5 & 100,0 & 21 & 100,0 & 2 & 100,0 & 28 & 100,0 \\
\hline
\end{tabular}

Estar com alguém que the demonstre segurança, carinho, conforto é uma forma de atingir as necessidades básicas de uma criança hospitalizada. Ter alguém por perto é uma das formas de reconstituir o ambiente familiar no ambiente hospitalar, facilitando assim sua recuperação, diminuindo dias de internação, tendo assim uma recuperação rápida. É o que revela 
os discursos dos profissionais da equipe de enfermagem a seguir:

\begin{abstract}
Proximidade com a mãe onde muitos cuidados realizados em casa continuam sendo feitos pela mesma (auxiliar de enfermagem).

Muito mais segurança ter alguém de vinculo maior (técnico de enfermagem).

Ter referência de casa em outro ambiente permanecer com a família ter carinho de mãe só mãe cuida com tanto cuidado (enfermeira).

A mãe sempre está próxima nos momentos de fragilidade diante da criança (escrituraria).
\end{abstract}

É preciso então, lutar para que a criança tenha o acompanhante durante a internação, para que tenha o seu direito garantido e a recuperação digna, com muito amor, carinho e segurança.

Quando nos referimos à criança, o esperado é que ela viva situação de saúde para crescer e desenvolver-se dentro dos limites de normalidade, porém quando nos defrontamos com ela na condição de doente, como todo ser humano, existe mudanças em seu comportamento (VIEIRA \& LIMA, 2002).

Para a criança, a hospitalização é um evento que altera todo seu estilo e sua forma de viver e enfrentar os possíveis problemas de internação "solitária".

As reações da criança à hospitalização variam segundo experiências prévias com doenças e separações dos familiares, hospitalizações anteriores, sistema de apoio disponível e a gravidade da doença (WHONG, 1999). Neste estudo, 60\% das enfermeiras, $50 \%$ dos escriturários, $88,1 \%$ dos técnicos e auxiliares de enfermagem referiram que no geral as crianças internadas não encontram dificuldades em permanecer no ambiente hospitalar, enquanto que somente os técnicos e auxiliares de enfermagem referiram as dificuldades da criança durante o período de internação era os momentos dos procedimentos, $33,3 \%$.

Com relação à opinião dos profissionais de enfermagem sobre adaptação da criança no ambiente hospitalar, para SILVA \& RIBEIRO (2000) a hospitalização de uma criança implica no afastamento do seu meio natural de convívio para uma realidade inteiramente diferente, onde as relações do cuidado desenvolvem sob novas óticas, que não aquelas que a criança esta habituada.

Esta compreensão também esteve presente em alguns discursos dos profissionais deste estudo, descritos a seguir:

A criança não está no seu mundinho, tendo que seguir regras que não fazem parte do seu dia-a-dia (auxiliar de enfermagem).

... tudo novo falta de confiança, insegurança ( auxiliar de enfermagem).
Portanto, é essencial a permanência de um cuidador pelo qual a criança tem afeto durante sua hospitalização.

Segundo BOWLBY (1984), enquanto a criança está na presença de uma figura principal de apego ou a tem ao seu alcance, sente-se segura e tranqüila, uma ameaça de perda gera ansiedade, e uma perda real gera tristeza profunda.

Esta perda, conseqüentemente pode interferir no curso do tratamento e recuperação da criança, prolongando ainda mais a permanência hospitalar.

Opinião dos profissionais da equipe de enfermagem sobre as facilidades e as dificuldades dos acompanhantes durante o período de internação da criança na unidade pediátrica.

Com relação às opiniões dos profissionais, quanto às facilidades dos acompanhantes desde a internação da criança até a sua recuperação, dos 28 profissionais pesquisados $100 \%$ das enfermeiras e $57,1 \%$ dos técnicos e auxiliares de enfermagem mencionaram acompanhar o tratamento e recuperação da criança como uma facilidade, enquanto que, $38,1 \%$ dos técnicos e auxiliares de enfermagem e $50 \%$ dos escriturários referiram que é manter o vinculo família/ criança.

A importância da permanência do acompanhante se sobressai na internação da criança, pois é através deste acontecimento que há uma recuperação mais rápida e diminuição da ansiedade dos familiares. É o que revela o discurso á seguir:

Por acompanhar o tratamento da criança
diariamente e ter informações quanto a
exame, procedimento (auxiliar de
enfermagem).

Além do vínculo criança-família, mantém-se a continuidade do cuidado e a integralidade da assistência à criança doente. Para as mães permanecer em período integral no hospital é a possibilidade de acompanhar a evolução da doença e as condições das crianças/ de seus filhos (COLLET \& ROCHA, 2003). Neste contexto, os discursos a seguir dos profissionais também revelam esta interação:

\section{Continuidade do vinculo família-criança... (auxiliar de enfermagem). \\ Estar ao lado da criança e estar atento a condições dela (técnico de enfermagem).}

Segundo OLIVEIRA \& ÂNGELO (2000), a permanência da mãe com seu filho na IC se move pela responsabilidade de prover o melhor para a criança, empreendendo uma luta para vencer a dificuldade de conviver com a dor sem se render a ela. As falas a seguir revelam a opinião dos profissionais quanto esta árdua responsabilidade:

Estando junto do filho mãe diz
dificuldade se supera
enfermagem).




\section{Estar sempre com o filho (enfermeira).}

$\mathrm{Na}$ realidade, a mãe sofre com os acontecimentos, ou seja, os sofrimentos da criança, porém ela não se rende, estando sempre forte e imbatível dia após dia do tratamento e recuperação do seu filho.

A mãe sendo o familiar mais próximo da criança doente, demonstrando o seu amor materno, codifica os sinais, sintomas e a preocupação quanto à gravidade da doença através do choro e das sensíveis mudanças no comportamento do seu filho durante o período de internação (OLIVEIRA, 1999).

Ao separar a mãe ou responsável da criança hospitalizada, estas caem no sofrimento e na angústia, deixando de viver e ser o que são num ambiente hostil deixando-a ainda mais vulnerável.

Com relação ao período em que o acompanhante permanece com a criança no hospital $40 \%$ das enfermeiras, $50 \%$ dos escriturários e $28,6 \%$ dos técnicos e auxiliares de enfermagem referiram que eles apresentam desgaste físico e emocional. Já $60 \%$ das enfermeiras e $23,8 \%$ dos técnicos e auxiliares de enfermagem consideraram que os acompanhantes têm grande preocupação em deixar a família/filhos em casa por estar no hospital, enquanto que somente os técnicos e auxiliares de enfermagem referiram que as dificuldades dos familiares e acompanhantes durante $o$ período de permanência no hospital eram aceitar os procedimentos realizados com as crianças.

Segundo COLLET \& ROCHA (2003), os sentimentos dos membros da família durante a hospitalização são ambivalentes; ao mesmo tempo em que permanecem acompanhando a criança, estes vão sendo superados ou suportados, tendo em vista o bem estar do seu filho. Também fazem tudo que está ao seu alcance para ficar no ambiente hospitalar, mesmo que isto signifique cansaço físico e sofrimento.

Em concordância com os autores referidos acima, os profissionais deste estudo também se referem sobre as dificuldades vivenciadas pelos acompanhantes durante a permanência na IC. É o que revela a fala a seguir:

Com muitos dias de internação a pessoa fica fisicamente cansada e acumula estresse e nem sempre informações são claras deixando-as ansiosa e insegura (auxiliar de enfermagem).

Com relação ao cuidado da criança, durante o período da internação hospitalar, SCHMITZ (2000) refere que os familiares se tornam críticos em relação à assistência e aos procedimentos e supervalorizam os pequenos detalhes do cuidado. Neste estudo alguns profissionais revelam algumas barreiras durante o período da assistência, especialmente na realização dos procedimentos técnicos. É o que revela os discursos abaixo:

Acompanhantes que são inseguros não aceitam o tratamento e interferem nos procedimentos (auxiliar de enfermagem)!
Não aceitar alguns procedimentos (auxiliar de enfermagem).

Segundo OLIVEIRA \& ÂNGELO (2000), apesar da satisfação em estar acompanhando a criança, este enfrenta tudo para cumprir o que define como seu dever. Principalmente, o de ser mãe, se entregando à missão prioritária de proteger, de poupar o filho de mais sofrimento, mesmo que esteja ausente de casa, deixando outros filhos e sua família, o que conseqüentemente, Ihe cause maiores preocupações e angústias.

A hospitalização da criança provoca na mãe sentimentos ambíguos por um lado, sente necessidade de acompanhar o filho doente, por outro lado, ressente-se de não poder dar assistência aos outros filhos que ficaram em casa (SIQUEIRA et al, 2002).

Neste estudo, os profissionais também referem que as dificuldades vivenciadas pela mãe durante a hospitalização é ter que deixar a sua família, revelados nas falas a seguir:

Muitas vezes são obrigadas a deixar outros filhos ao cuidado de outras pessoas (auxiliar de enfermagem).

Se tiver mais filhos esta fica dividida entre o filho que está internado e o que fica em casa (técnico de enfermagem).

Além de deixar sua família para ficar com a criança hospitalizada, o acompanhante enfrenta a dificuldade em se adaptar com o ambiente hospitalar, o qual não the oferece meios de bem estar, como repouso, alimentação, higiene adequada, como abordado na seguinte fala:

Sem alojamento, manter a família em casa, sem local adequado para descanso, número elevado de dias de internação das crianças, sem local adequado para realizar as refeições, estresses, falta de informação sobre o tratamento (enfermeira).

Apesar das dificuldades vivenciadas pelas mães na unidade pediátrica, os esforços dos profissionais em maximizar proteção ao binômio são contínuos, mesmo que no dia-a-dia existam os limites físicos e estruturais.

A permanência do acompanhante ao lado da criança hospitalizada é muito importante, tanto para criança que se sentirá mais segura e amparada, quanto para o acompanhante que estará participando ativamente deste processo de recuperação (SIQUEIRA et al., 2002).

Opinião dos profissionais da equipe de enfermagem sobre as facilidades e as dificuldades encontradas durante a permanência da criança $e$ acompanhantes na unidade pediátrica.

Com a presença dos acompanhantes na unidade pediátrica surgem facilidades para a equipe de enfermagem, pois os acompanhantes têm 
explorado suas funções no setor de pediatria para além de auxiliar a criança a enfrentar o processo terapêutico. Mas também têm realizado cuidados, porque eles sabem do que a criança gosta, tem mais paciência, devido à falta de tempo e a sobrecarga de trabalho dos profissionais na unidade (COLLET \& ROCHA, 2003).

Quanto às facilidades dos profissionais durante a permanência da criança e do acompanhante $57,1 \%$ referiram que estes auxiliavam a equipe na realização dos procedimentos e $39,3 \%$ responderam que os acompanhantes auxiliavam na recuperação da criança.

A presença do acompanhante é considerada pelos profissionais, como um facilitador, principalmente durante a realização dos procedimentos, como revelado nos discursos a seguir:

Como a falta de recurso é uma realidade a ajuda da mãe ou familiar é de extrema importância para a recuperação da criança (auxiliar de enfermagem).

Criança se sente mais segura por estar acompanhada se torna mais fácil para nós durante um procedimento e cuidados em geral (auxiliar de enfermagem).

Mãe cuida melhor criança mais calma (enfermeira).

Além de auxiliar nos procedimentos diários, a presença do acompanhante faz com que a criança tenha uma recuperação rápida e melhor, promovida pelo forte vínculo família-criança (JUNQUEIRA, 2003).

Segundo OLIVEIRA \& ANGELO (2000) a mãe sofre assistindo ao sofrimento, sofre junto ao filho e sofre pelo fato de vê-lo sofrendo. Em especial nas situações em que é submetido a procedimentos terapêuticos dolorosos na sua frente, sem que ela possa fazer alguma coisa para evitar ou minimizar a dor dele, sendo este um dos principais motivos da resistência da mãe para efetivamente colaborar no cuidado da criança.

Em meio a tanto sofrimento, resistência à proteção do acompanhante, prevalece na internação conjunta sua presença, a qual favorece recuperação, auxilia nos procedimentos e com isso a criança melhor responde na terapêutica.

GUARESCHI \& MARTINS (1997) afirmam que com a presença do acompanhante a criança se sente mais segura. Os acompanhantes ajudam no cuidado da criança. É neste momento que se favorece oportunidade para educar os acompanhantes quanto aos cuidados com seus filhos e, a equipe pode dedicar-se maior tempo para as crianças desacompanhadas.

Portanto, ter acompanhantes para as crianças não são apenas dificuldades pela sua presença, mas também há facilidades na prática diária nas unidades pediátricas.

Para KAKEHASHI \& SILVA (2001) a presença constante dos familiares no ambiente do cuidado, exigiu também dos membros da equipe de assistência novas habilidades, no que se refere ao estabelecimento de relações interpessoais com os mesmos, à criança, como também no sentido de capacitá-los ao autocuidado, para que a experiência hospitalar seja por eles considerada não só um momento de sofrimento, mas também de crescimento pessoal e fortalecimento do vínculo com a criança.

Quanto às opiniões dos profissionais sobre as dificuldades encontradas durante o período de permanência da criança e do acompanhante na unidade pediátrica, cerca de $43 \%$ referiram que era realizar os procedimentos e manter o seguimento das rotinas da IC pelos acompanhantes e $28,5 \%$ era se adaptarem com a presença dos acompanhantes.

Com a implementação da mãe acompanhante na unidade pediátrica, o processo de trabalho da equipe de enfermagem defrontou-se com várias dificuldades, entre elas, a realização dos procedimentos e o cumprimento das rotinas da IC pelos acompanhantes, exemplificado nas seguintes falas:

Difícil realizar procedimentos, pois nem sempre os acompanhantes são informados sobre tratamento, dificultando o trabalho, ou nem sempre aceitam as normas da internação conjunta onde se tem hora, local para fazer tudo (auxiliar de enfermagem).

Pais que assustam não colaboram nos procedimentos passando insegurança para a criança (auxiliar de enfermagem).

Orientação da rotina e normas do setor há muito desrespeito gerando mais dificuldade para equipe (auxiliar de enfermagem).

Difícil manter separado o que é trabalho da enfermagem e trabalho da mãe em relação ao cuidado mais complexo, temos dificuldade de orientar e se fazer entender as normas e rotinas... (enfermeira).

Mãe inibe a desempenho da enfermagem no cuidado (enfermeira).

O desafio por parte dos profissionais em adaptarem-se com a presença dos acompanhantes e, também fazê-los seguirem a rotina da unidade não é tarefa tão fácil como parece, pois estes muitas vezes podem não aceitar o que deve ser feito e também tem em dificuldade seguir as normas e rotinas da instituição.

Segundo COLLET \& ROCHA (2003), os profissionais têm grande dificuldade para orientar os acompanhantes, para que estas normas sejam seguidas. Mas, quando flexionadas de acordo com cada caso, as tensões tendem a diminuir, as regras formais são reconstruídas por meio de processo de cruzamento com as regras informais criadas nas negociações, veladas ou explícitas, vão sendo estabelecidas em situações singulares no cotidiano da unidade.

Estas negociações podem gerar desgaste psicológico da equipe ao ter que atender as necessidades individuais nem sempre o profissional está preparado para gerenciar os conflitos, podendo ficar insatisfeitos consigo mesmo e com os próprios acompanhantes. Mas, se houver uma equipe 
multiprofissional os conflitos conseqüentemente diminuirão e as relações equipe-família-criança poderão ser satisfatórias.

Opinião dos profissionais da equipe de enfermagem sobre as facilidades e as dificuldades de trabalho com relação à infra-estrutura e planta física da unidade pediátrica durante o período de permanência da criança e acompanhantes na Internação Conjunta.

A infra-estrutura e a planta física da unidade pediátrica após a implementação da internação conjunta demonstrou maiores necessidades tanto para a criança internada quanto para o acompanhante.

Os profissionais deste estudo consideraram que a infra-estrutura dificulta a execução da rotina da IC, $71 \%$ e apenas $18 \%$ responderam que facilitava.

Além das dificuldades referidas nos discursos dos profissionais sobre a infra-estrutura da unidade pediátrica para as crianças e acompanhantes alguns também referem que existem ambientes que favorecem a permanência. É o que revela os discursos a seguir:

\section{Repouso falta de uma acomodação melhor (escrituraria). \\ Repouso péssimo com cadeiras desconfortável enfermaria apertada (auxiliar de enfermagem). \\ Não damos condições humanas para que a mãe possa descansar, algumas mães ficam muito cansadas quando permanecem muitos dias (enfermeira). \\ Sala de recreação, o qual segundo... (auxiliar de enfermagem). \\ Alimentação de boa qualidade (escrituraria).}

Mesmo que a infra-estrutura não favoreça melhores acomodações tanto para as crianças como para os acompanhantes, é necessário manter um ambiente agradável em que a criança possa executar o brincar.

Segundo SILVA \& RIBEIRO (2000), quando o cuidado vem acrescido de brincadeira, e este é realizado no ambiente em que a criança se encontra, transmite maior segurança à criança. O brincar facilita o acesso à atividade simbólica e a elaboração psíquica de evidências do cotidiano infantil, pois através das brincadeiras constrói o cuidar, o adoecer durante a hospitalização (JUNQUEIRA, 2003).

O cuidado com a criança é fundamental, mas também o acompanhante não deve ser esquecido, pois estes precisam estar bem nutridos para poderem permanecer no hospital. De acordo com COSTENARO et al (1998), a permanência contínua do acompanhante pode ser mantida se as suas necessidades físicas e psíquicas são supridas, com isto evita afastamento da criança, favorecendo a diminuição da ansiedade da criança e proporciona conforto a ambos, além de levar o acompanhante a se sentir de certa forma mais bem cuidado.
A infra-estrutura e a planta física são reguladas e adaptadas de acordo com as necessidades de bem estar, melhor cuidado tanto para a criança quanto para a acompanhante, em uma luta constante para humanizar a assistência.

Opinião dos profissionais da equipe de enfermagem sobre a influência dos acompanhantes para a criança durante a execução dos procedimentos na unidade pediátrica.

Quanto a influencia do acompanhante sobre a criança durante a execução dos procedimentos $83 \%$ dos profissionais responderam que ele tem influencia sobre a criança.

Os discursos a seguir revelam algumas dificuldades encontradas pela equipe durante a realização dos procedimentos, principalmente quanto à resistência do acompanhante em determinados procedimentos, como a punção venosa. Mas também algumas falas apontam a importância em manter o acompanhante durante os procedimentos, pois geralmente a criança fica mais tranqüila e colaborativa:

Às vezes não entendem o que está sendo feito ou querem que se faça alguma coisa como puncionar veia... (auxiliar de enfermagem).

Tem muitas mães que não aceitam os procedimentos dos auxiliares impondo limites (auxiliar de enfermagem).

Algumas mães interferem principalmente na hora de puncionar veia querendo escolher o lugar tendo as vezes que puncionar mais que uma vez (auxiliar de enfermagem).

Com a mãe ao lado da criança tornam-se mais colaborativas menos irritadas, confiantes (técnico de enfermagem).

KAKEHASHI \& SILVA (2001, p.19), referem que além da família influenciar nos procedimentos ela pode também permanecer ao lado da criança para ajudá-la e geralmente a família espera dos profissionais que:

“... alem de resolver o problema clínico da criança, ser tratada com atenção. Não se trata de passar uma enorme quantidade de orientações, mas a partir daquilo que eles já conhecem ajudar na busca de soluções; não se trata de evitar os erros, mas o direito de crescer através e apesar deles, sem por isso ser julgada e rotulada pejorativamente, não se trata de evitar sofrimentos que por vezes são inerentes à situação e à condição humana, mas de proporcionar apoio nas situações de dor, para que possa mobilizar adequadamente sua energia; não se trata de sentir piedade, mas de nos mostrarmos solidários, enfim, de preservar a sua dignidade mesmo em condições diversas...". 
Cabe salientar que esta pesquisa refere-se apenas a descrição das opiniões dos profissionais de uma unidade pediátrica de um hospital escola e que pode servir de referência para a realização de novas pesquisas utilizando outras metodologias.

De acordo com os resultados desta pesquisa parece ser necessário buscar meios que coloque o acompanhante na participação do cuidado para que sua presença não seja uma forma de conflitos na prática do procedimento, mas sim uma forma de colaborar na recuperação da criança internada.

A internação conjunta em pediatria é uma das práticas de maior valor na assistência da criança hospitalizada, promovendo a humanização do cuidar da criança e de sua família, pois há uma recuperação rápida e diminui a ansiedade por parte dos familiares.

Nesta pesquisa os profissionais que prestam assistência à criança são todas do sexo feminino, mostrando também a necessidade de ter a presença do sexo masculino no processo do cuidara.

A equipe apresenta dificuldades para manter o seguimento das normas e rotinas, pois os acompanhantes mostram-se resistentes e não seguem as normas orientadas. Parece ser preciso ter uma boa relação com os acompanhantes demonstrando a necessidade de educação continuada para os profissionais para a melhoria das relações humanas e interpessoais, não apenas em relação ao acompanhante, mas também com toda equipe multiprofissional.

Enfim é necessário repensar no modo como os acompanhantes estão fazendo seu papel e ao mesmo tempo como os profissionais atendem a criança com alguém por perto, buscando assim implementar as normas e as rotinas de acordo com a especificidade da situação em que se encontra.

\section{REFERÊNCIAS}

BOWLBY, J. Apego. São Paulo: Martins Fontes: 1984. BRASIL. Conselho Nacional de Saúde. Diretrizes e Normas regulamentares de pesquisa envolvendo seres humanos. Resolução n. 196/1996 Brasília, DF, 1996.

BALDINI, M.S.; KREBS,V.L.J. A criança hospitalizada. Pediatria, v.21, n.3, p.182-190, 1999.

CASTRO, P. R. M. A hospitalização infantil: estudo sobre o preparo, conhecimento e atuação de uma equipe de enfermagem do hospital de Londrina. 45p. Londrina, 1991. Monografia (Especialização em Metodologia do Ensino). Universidade Estadual de Londrina.

COLLET, N.; ROCHA, M. M. S. Participação e autonomia da mãe no cuidado do filho hospitalizado. Rev. Brasileira de Enfermagem, vol. 56, n.3, 2003.

COSTENARO, R.G.S.; DAROS,A.; ARRUDA,E.N. O cuidado na perspectiva do acompanhante de crianças e adolescentes hospitalizados. Rev. Enf. Anna Nery, v.2, n.1/2, p.111-126, 1998.
FERREIRA, E. A. et al. Um estudo bibliográfico sobre o apego mãe e filho: bases para assistência de enfermagem pediátrica e neonatal. Rev. Lat. Am. Enf, v.6, n.4, p.111-116, 1996.

GOMES, A.J.S.; RESENDE, V.R. O pai presente: o desvelar da paternidade em uma família contemporânea. Psicologia teoria e pesquisa, v.20, n.2, p.119-125, 2004.

GUARESCH, A.P.D.F.; MARTINS,L.M.M. Relacionamento multiprofissional $x$ criança $X$ acompanhantes: desafio para equipe. Rev. Esc. Enf. USP, v.31, n.3, p.423-436, 1997.

HUERTA, E. D. P. N. A experiência de acompanhar um filho hospitalizado: sentimentos, necessidades e expectativas manifestadas por mães acompanhantes. 218p. São Paulo, 1984. Dissertação (Mestrado). Escola de Enfermagem da Universidade de São Paulo. IMORI, M.C. et al. Participação dos pais na assistência à criança hospitalizada: revisão crítica da literatura. Act. Paul. Enf., v.10, n.3, p.37-43, 1997.

JUNQUEIRA, M.F.P.S. A mãe, seu filho hospitalizado e o brincar: um relato de experiência. Estudo Psic., v.8, n.1, p.193-197, 2003.

KAKEHASHI, Y. T.; SILVA, V. C. O cuidar da criança e da família, das reflexões teóricas à sua aplicação na prática profissional do cotidiano. Saúde e Desenvolvimento, v.3, n.1, p.15-20, 2001.

OLIVEIRA, B. R. G.; COLLET, N. A criança hospitalizada percepção das mães sobre o vínculo afetivo criança- família. Rev. Lat. Am. Enf., v.7, n.5, p. 95-102,1999.

OLIVEIRA, I.; ANGELO, M. Vivenciando com o filho uma passagem difícil e reveladora: a experiência da mãe acompanhante. Rev. Esc. Enf. USP, v.34, n.2, p. 202-204, 2000.

SOBECC - Sociedade Brasileira de Enfermeiros em Centro Cirúrgico. Referência nacional em gestão humanizado. Rev. SOBECC, v.7, n.4, p.16-17, 2002.

SCHMITZ, R. M. E. A problemática da hospitalização infantil: aspectos psicológicos. In: SCHMITZ, E. A. et al. A enfermagem em pediatria e puericultura, Rio de Janeiro: Atheneu. 2000.

SILVA, C.C.; RIBEIRO,N.R.R. Percepções da criança acerca do cuidado recebido durante a hospitalização. Rev. Bras.Enf, v.53, n.2, p.311-323, 2000.

SIQUEIRA, L.S.; SIGAUD, C.H.S.; RESENDE, M.A. Fatores que apóiam e não apóiam a permanência de mães acompanhantes em unidade de pediatria hospitalar. Rev. Esc. Enf. USP, v.36, n.2, p.270-275, 2002.

VIEIRA, M.A.; LIMA, R.A.G. Crianças e adolescentes com doença crônica: convivendo com mudanças. Rev. Lat. Am. Enf., v.10, n.4, p.552-560, 2002.

WHONG, D.L. Enfermagem pediátrica: elementos essenciais à intervenção efetiva. 5 ed. Rio de Janeiro: Guanabara Koogan, 1999. 
*Artigo baseado em Trabalho de Conclusão de Curso - TCC apresentado ao Curso de Enfermagem da Universidade Estadual de Londrina Paraná.

${ }^{1}$ Acadêmica do $4^{\circ}$ ano do curso de Enfermagem da Universidade Estadual de Londrina, Londrina, Paraná, Brasil.

${ }^{2}$ Enfermeira. Mestre em Enfermagem. Professora do Departamento de Enfermagem da Universidade Estadual de Londrina, área de Saúde da Criança e do Adolescente. Londrina, Paraná, Brasil. Endereço para contato: Av. Robert Koch, n. 60, Vila Operária, Centro de Ciências da

Saúde, Departamento de Enfermagem, $1^{\circ}$ andar, Londrina, Paraná, CEP: 86.038-440. Email: ropimentaferrari@uel.br

Texto original recebido em 25/01/2005

Aprovado para publicação em 29/04/2005 